Article

\title{
Occupant Behavior for Energy Conservation in Commercial Buildings: Lessons Learned from Competition at the Oak Ridge National Laboratory
}

\author{
Amanda Ahl ${ }^{1, *}$, Gina Accawi ${ }^{2}\left(\mathbb{D}\right.$, Bryce Hudey $^{2}$, Melissa Lapsa ${ }^{2}$ a and Teresa Nichols ${ }^{2}$ \\ 1 Department of Innovation Science, School of Environment and Society, Tokyo Institute of Technology, \\ 3-3-6 Shibaura, Tokyo 105-0023, Japan \\ 2 Oak Ridge National Laboratory, Sustainable ORNL Program, 1 Bethel Valley Rd., Oak Ridge, TN 37830, USA; \\ accawigk@ornl.gov (G.A.); hudeybd@ornl.gov (B.H.); lapsamv@ornl.gov (M.L.); \\ teresaannnichols@gmail.com (T.N.) \\ * Correspondence: ahl.a.aa@m.titech.ac.jp
}

Received: 22 April 2019; Accepted: 4 June 2019; Published: 14 June 2019

check for updates

\begin{abstract}
Accompanying efforts worldwide to deploy sustainable building technologies shows a pressing need for expanded research on occupant behavior. Discourse is lacking concerning drivers of occupant behavior for energy conservation, especially in the case of commercial buildings. This paper explores potential determinants of occupant behavior for energy conservation in commercial buildings. This is investigated in a case study of a two-month energy conservation competition involving eight office buildings at the Oak Ridge National Laboratory. Four buildings achieved energy savings based on the previous year's baseline. Potential challenges and success factors of occupant behavior for energy conservation during the competition were explored based on an explanatory research design incorporating energy data, participant interviews, and surveys. The findings suggest that both social and technological aspects may be important drivers of energy conservation. The determinants of occupant behavior for energy conservation in commercial buildings suggested for further research include bottom-up involvement, stakeholder relationship management, targeted information, real-time energy visualization, and mobile social platforms. This paper presents initial implications, with a need for further research on these propositions and on their impacts on occupant behavior. This paper aims to contribute to both academia and practitioners in the arena of commercial building sustainability.
\end{abstract}

Keywords: occupant behavior; energy conservation; sustainable buildings; behavioral change; commercial building; competition

\section{Introduction}

There is an emerging area of academic discourse integrating social dynamics and behavior in the analysis of technical systems [1,2], hereon referred to as sociotechnical systems. Buildings are examples of such systems [3,4], with a complex interplay of social, technical and environmental factors. In the United States, residential and commercial buildings account for $40 \%$ of national energy consumption [3]. Over $20 \%$ of national consumption is attributable to commercial buildings, which also show the highest energy intensity and growth rates [5]. With pressures of climate change and sustainability goals, there have been numerous efforts to improve building energy efficiency via technological modifications. For example, building energy management systems (BEMS) integrate smart technologies to manage energy consumption [6]. However, the impact of technological innovation in buildings also depends on occupant behavior, indicating a sociotechnical system core [6,7]. Occupant behavior in buildings is a 
relatively new but growing research area, with a majority of literature focusing on energy conservation in residential buildings [8-12].

Research on occupant behavior in commercial buildings has shown recent growth. An example of a valuable contribution is the field study of occupant behavior in a research office building by Pivac et al. [13]. The authors analyzed thermal comfort and energy consumption patterns during a typical working day, finding that thermal comfort largely depends on occupant behavior, such as natural ventilation [13]. The authors further noted a need for further research on energy conservation approaches and on drivers of occupant behavior change [13]. While research on occupant behavior in buildings has been expanding, a recent study showed that only approximately $7 \%$ of this research explores the determinants of behavioral change [8]. There is a particularly large research gap pertaining to these drivers in the context of energy conservation in commercial buildings, and filling this gap can contribute to further reducing energy demands and associated carbon emissions. In addition, several authors $[10,11]$ have highlighted a need to further quantify energy consumption changes due to specific intervention techniques. One potential technique is competition, based on information and comparative interventions, which is also an area in need of further analysis in the setting of commercial buildings.

There is a clear research gap pertaining to determinants of occupant behavior and intervention technique impacts for energy conservation in commercial buildings. This paper aims to contribute to reducing this gap by exploring determinants of occupant behavior in the context of a specific intervention-an energy conservation competition. The potential challenges and success factors of occupant behavior for energy conservation were explored based on a case study of an energy conservation competition at the Oak Ridge National Laboratory (ORNL). A triangulated research design was adopted in order to develop useful insights by leveraging quantitative energy data alongside qualitative analysis of occupant perceptions. At large, this paper aims to contribute to the literature with practical implications related to occupant behavior, based on an analysis of a real-life energy conservation intervention. These implications may, in turn, be further explored in academia as well as by practitioners. As follows, the relevant literature related to residential buildings, commercial buildings, as well as behavioral/social theory is reviewed in Section 2. Second, the case and methodology of this paper are described in detail in Section 3. Thereafter, the results are presented based on quantitative and qualitative data analyses in Section 4 . These results are discussed with a basis in theory in Section 5, concluding with implications for occupant energy behavior in commercial buildings and suggestions for future research in Section 6.

\section{Literature Review}

\subsection{Occupant Behavior in Residential Buildings}

In a meta-analysis of studies focusing on occupant behavioral change for energy conservation in households, Delmas et al. [14] found an average consumption reduction of 7.4\%, with the most effective driver being real-time feedback on energy use and environmental impacts. Several other authors have explored incentivization strategies, such as occupant behavior related to carbon emissions reduction [15], the impact of non-price incentives on energy conservation [16], and competition for energy behavior modification among households $[4,17,18]$. Sintov et al. [18], for example, analyzed an energy conservation competition at a student dormitory, finding a $6.4 \%$ average reduction influenced by heightened environmentalism and perceived social norms. Konis et al. [4] found that competitions leveraging trusted community members and social norms in a continuous engagement with participants showed higher success rates for energy conservation in student dormitories.

These findings in the literature indicate that, in addition to economic savings, environmental and social dimensions also influence occupant behavior. Smart phone applications and interactive interfaces for social learning and communication can contribute to occupant behavior change [7]. Smart technologies and applications can also enable real-time feedback as well as model-based indications 
of future outcomes, which can be important pillars in behavior intervention strategies [6]. Real-time feedback and comparison with neighbors can contribute to competitiveness, which is also a factor in behavioral change for reduced electricity consumption [4,17].

Considering the influence of occupants on building energy conservation, occupant behavior would be an important factor to also incorporate in building energy simulations [13]. For example, in a series of simulations, Becherini et al. [19] found that load reduction and natural ventilation in historic buildings can improve the effects of thermal coating. The authors modeled and suggested several scenarios through which thermal coating and occupant behavior can contribute to building thermal performance. In simulations by Roberti et al. [20], the authors similarly found that natural ventilation can add to energy conservation in a historic building, in addition to external insulation, building airtightness, and windowpane replacement measures. Nonetheless, as highlighted by Pivac et al. [13], simulation outputs are uncertain without fieldwork that also incorporates end-users.

It is important to note that energy behavior varies in a number of ways between commercial and residential buildings. The key differences include the lack of monetary incentives for energy use reduction for workplace occupants $[14,21]$, and the incorporation of managerial system control, group norms, role models, and work-related activities in commercial buildings [11]. As follows, the research domain of occupant behavior related to energy consumption in commercial buildings is explored further.

\subsection{Occupant Behavior in Commercial Buildings}

Occupant behavior is a necessary consideration in addition to technology for effectual, cost-effective energy conservation strategies [3,4,8-10]. There is a wide consensus in academia that there is a need of further research on occupant behavior, with a particular gap being the context of commercial buildings [10]. Building occupants have a significant influence on unregulated loads, such as plug loads $[4,5]$, which if not properly managed, can negatively impact energy conservation program efforts. In literature reviews by Hong et al. [11] and Zhang et al. [8], the behavior-related potential energy savings in commercial buildings was found to be in a range of $5-30 \%$.

While there is less academic dialogue on the influence of occupant behavior on energy consumption in commercial buildings, the discussion is growing [11]. For instance, in exploring strategies to reduce occupant-controlled plug-loads in commercial buildings, Rafsanjani et al. [5] developed non-intrusive load-monitoring techniques to link power changes to occupant events over time. Staats et al. [22] recorded a $6 \%$ reduction in gas consumption in a university office building following an information intervention. This was based on brochures encouraging employees to adjust thermostats, collective graphic feedback, personalized feedback to all participants, and reminders to adjust thermostats over the Christmas break [22]. Kosonen \& Kim [10] focused their review on energy behavior intervention in the context of commercial buildings, and found that the most successful programs adopt peer comparisons to influence occupant behavior. The authors found that the least successful programs share untargeted information, such as general letters on energy use associated with various plug load devices, and conservation tips [10].

Information coupled with comparative interventions, such as competitions, have been increasingly studied and shown to be effective for energy conservation in commercial buildings [8]. One example is the five-month electricity conservation competition, I've got the power, carried out among the floors in the L'Oréal Headquarters in New York City [23]. With a four-step approach, including educating, motivating, recognizing, and rewarding, energy conservation was achieved at an average of $9 \%$, with a $37 \%$ reduction on the winning floor [23]. While there is clear potential, there is still a need of further research on the relationship between social influence and competition, and mapping of behavioral drivers of energy conservation [24]. In discussions on such drivers, it would be useful to leverage theories pertaining to behavior and social dynamics. 


\subsection{Behavioral Change and Social Dynamics}

Occupant behavior is a multi-layered phenomenon. Awareness of sustainability alone is insufficient for behavioral change, which also requires community engagement from the bottom up [24-27]. It is important to address barriers in specific community segments inhibiting a desired behavior [28], which may include entrenched habits, comfort preferences, deficient awareness or lacking information in the context of energy use in buildings [29]. It is clear that occupant behavior, if managed well, could contribute to energy conservation and building sustainability. However, behavior is a multifaceted and complex topic, and there is a need of further theory-based discussion in academia on the underlying determinants of energy behavior change $[4,10]$.

There are several theoretical frameworks which attempt to integrate the multiple facets of behavior and offer insights on the area. For example, in the 6-P Framework by Too et al. [26], six elements were proposed to encourage sustainable community practices: Psychological (awareness of action consequences), physical (green facilities), personal (perceived benefits), public perception (social norms), price (costs and gains), and policy (top-down management) elements. Furthermore, the theory of planned behavior (TPB) [30] is useful in investigating the intention of occupants to carry out certain behaviors, based on attitude (perception of consequences), subjective norms (public perception), and perceived control (perceived difficulty of a behavior). In the theory of interpersonal behavior (TIB), past habits, facilitating conditions, such as technology, and intention influence behavior [31].

The elements of frameworks, such as the TIB and TPB, can be used to analyze human habit, which has gained attention in environmental literature. Habit is defined in this paper as an act that has been learned and becomes automatic in specific situations. Habits impact frequent actions in several systems, such as waste disposal [27], transportation patterns [32], and energy consumption [15]. Knussen \& Yale [33] found that analyzing attitudes towards a non-habitual action is insufficient in predicting intention in the TPB, pointing to habitual behavior being less likely to be driven by conscious reasoning. In this context, Konis et al. [4] applied the TPB in investigating a student dormitory energy conservation competition. The authors found that higher self-efficacy enables short-term energy conservation but higher rebound effects, while stronger group identification and public perception was linked to higher as well as sustained conservation.

At large, understanding habitual behavior is important for long-term behavioral change. Developed by Frank [34], the five-domain experiential system explores long-term behavioral change as a multi-experiential transformation. The system includes emotional (feeling), mental imagery (worldview), sensorimotor (actions and perceptions), linguistic (rational reasoning), and communicational (message perceptions) domains [34]. Approaches to energy behavior change have at large been top-down, utilizing information and rationality-based interventions [25-27,34]. Such interventions leverage the communicational and linguistic domains. However, Frank [34] highlighted that not only such factors, but also the emotional and mental imagery domains, continue to mold behavior and require further consideration in sustainability initiatives.

\section{Materials and Methods}

The case study of this paper is based on the Battle of the Buildings (BoB), a building electricity conservation competition held July-September of the fiscal year 2016 (FY16) at ORNL. Case studies are valuable when exploring real-life contexts with many potential variables and perspectives $[35,36]$. There are multiple aspects of occupant behavior which require both objective and subjective data for which a mixed method incorporating quantitative and qualitative approaches is beneficial [37]. In this paper, an explanatory design was adopted, whereby qualitative data from interviews and surveys were analyzed and used to discuss the quantitative findings of energy consumption changes during the competition. The methodology is based on three measures: (1) Energy consumption data collection followed by, (2) competition participant interviews and, (3) surveys. The described approach was utilized for methodological triangulation, as recommended by Eisenhardt [38] and Yin [36] for improved validity of case study results and any ensuing theoretical propositions. The methodological 
flow of this paper can be seen in Figure 1. The case and the three pillars of the methodology are described further as follows.

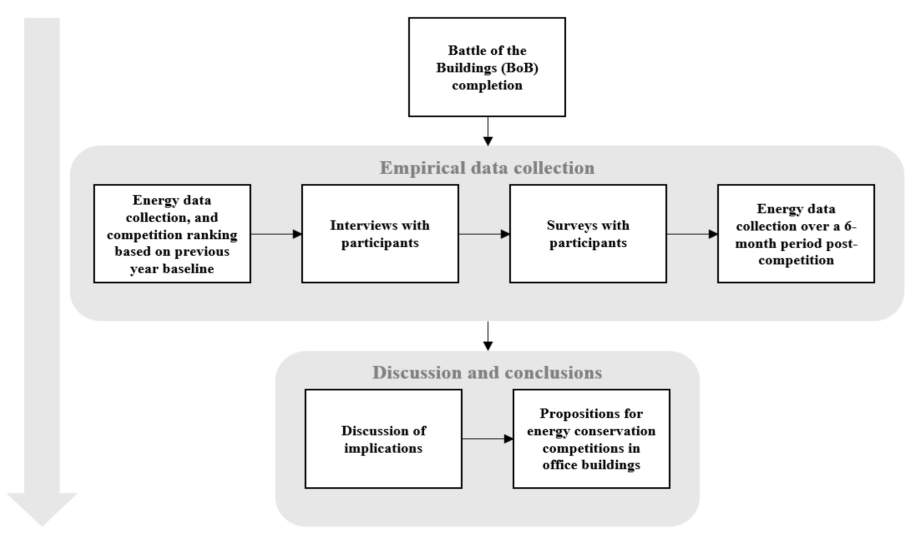

Figure 1. Simplified schematic overview of the methodological approach.

\subsection{Case Description and Energy Data}

The managerial goal of the BoB was to increase awareness of ORNL's smart meter data collection, as well as of occupants' potential to impact energy utilization. Eight buildings on campus were selected to compete. More information on each building can be seen in Table 1. The buildings are notated as A, B, C, etc. for anonymity. Building selection was primarily based on building utilization and area similarity, and secondarily, on occupancy. The main space utilization involved administrative work and no operations necessitating power-intensive laboratory equipment. This was considered important due to the unfair disadvantage such occupants would have in terms of the ability to conserve energy without negatively affecting experiments and their work at ORNL. Energy conservation was measured based on accumulated power savings relative to corresponding months in the FY15 baseline, and was measured based on smart meters, with weather effects normalized to account for extreme conditions. The competition rankings were based on percentual power consumption changes relative to this baseline. The range of occupancy in the selected buildings (14-44) is likely to have affected the total energy conservation in the buildings and potentially to have impacted the social dynamics of the buildings. For example, regular communication may be easier among participants in buildings with lower occupancy. However, as the rankings were based on percentual reduction as opposed to the total reduction quantity, it can be suggested that the impact of occupancy ranges was reduced, supporting building comparison in the competition.

Table 1. Building information.

\begin{tabular}{ccccc}
\hline Building & Business Activity & Area Gross (SQF) & Occupancy & Interviewees \\
\hline A & Internal Audit \& Legal Directorates & 6988 & 15 & 2 \\
\hline B & Building Technologies Research \& Integration Center & 6989 & 16 & 3 \\
\hline C & Benefits and Retirement Services & 6995 & 15 & 4 \\
\hline D & Safeguard and Security Technology Center & 6995 & 14 & - \\
\hline E & Computational Biology and Bioinformatics & 6998 & 29 & 1 \\
\hline F & General Office Building & 6998 & 18 & - \\
\hline G & Life Sciences Data Analysis & 6996 & 44 & 1 \\
\hline H & Training Center & 6995 & 15 & - \\
\hline
\end{tabular}

During the BoB, a real-time online visualization of performance was available to all participating buildings. A screenshot with approximately 14 days remaining of the competition is shown in Figure 2 . As a prize, a certificate and celebratory lunch was awarded to the winning building's occupants, along with bragging rights. Data related to energy consumption during the $\mathrm{BoB}$, as well as six 
months following the completion of the BoB, were collected. The post-competition data were used for discussions on potential rebound effects.

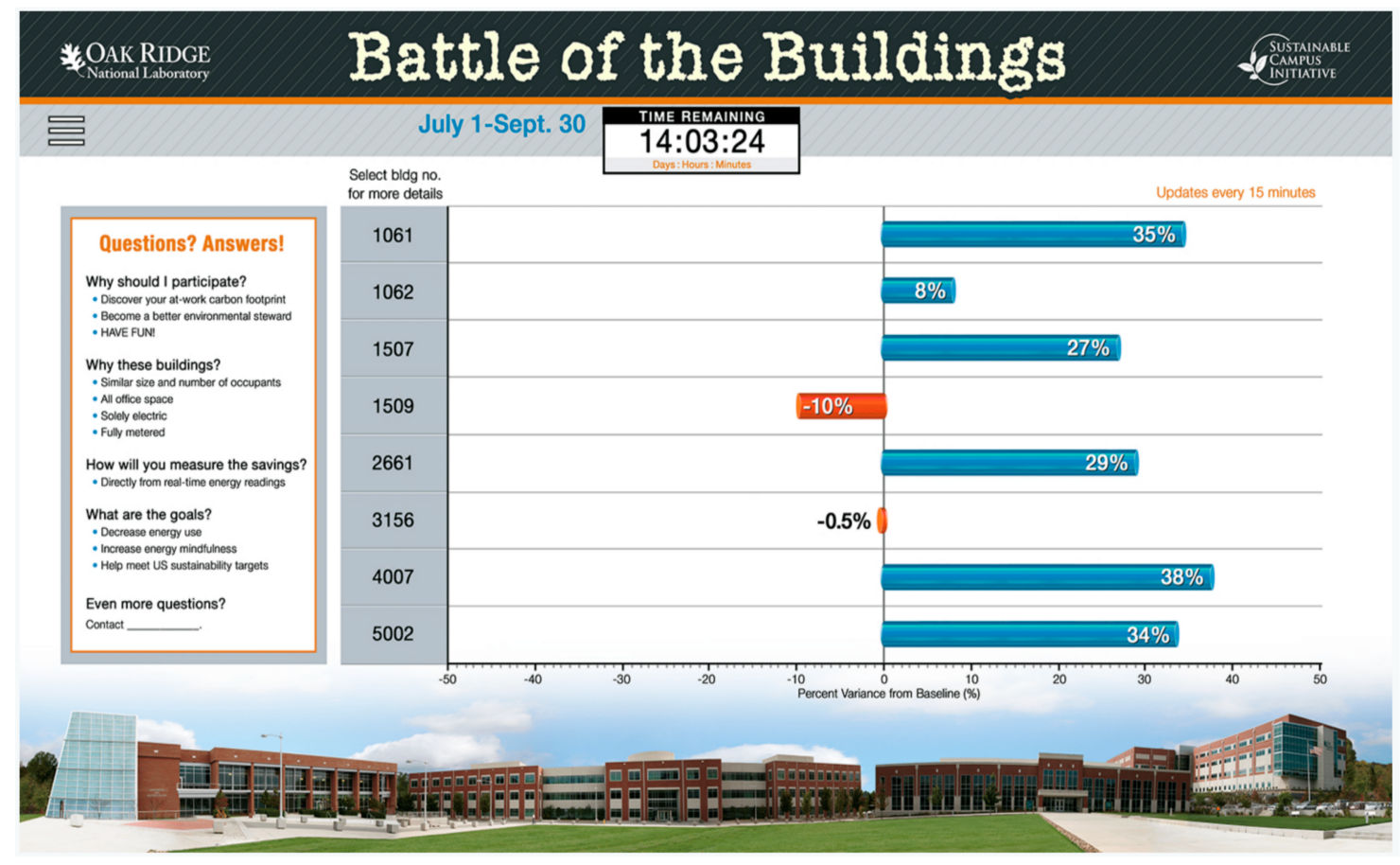

Figure 2. Screenshot of real-time competition energy conservation visualization.

\subsection{Interviews}

Based on the availability of building representatives, five out of the eight participating buildings were included in the interview phase, and carried out the week following the end of the BoB. Semi-structured, face-to-face interviews with open-ended questions were carried out aiming to investigate perceived challenges and success factors for energy conservation during the competition. Interviews included between one and four interviewees per building, and all interviewees representing an individual building were interviewed as a group. The interview was structured based the following key questions:

- What were key drivers of energy conservation during the competition in your building?

- What were key challenges of energy conservation during the competition in your building?

What do you think of the duration of the competition (too short, just right, or too long)? Please explain.

- Would you join an energy conservation competition again? Please explain.

- $\quad$ Do you have any further comments?

The interviews were based on these key questions, as well as follow-up questions when relevant. Based on a content analysis of transcripts, the frequency of key factors was investigated. Factors mentioned by occupants in two or more buildings were incorporated in two comparative tables of reported, (1) key challenges and, (2) key success factors. Insights gained in interviews were thereafter integrated in the surveys of this study, and discussed further as follows.

\subsection{Survey}

Thereafter, a survey was shared with the occupants ( $\mathrm{N}=174$ individuals) in all eight buildings to complement the interviews and decrease confirmation and interviewer bias. The survey was open for 
two weeks following the interview phase, with a reminder email sent after one week. On a five-point Likert scale, respondents were asked to rate the level of importance of challenges and success factors of energy conservation experienced during the competition. Chi-square tests were used to explore the statistical significance of these results. The factors included in the surveys were based on the interviews as well as on indications in the literature pertaining to the potential drivers and challenges of occupant behavior for energy conservation. In addition, a four-point Likert scale was used to explore levels of (1) confidence and (2) activity in conservation efforts before and after the BoB. Two-tailed paired sample t-tests were used to explore the significance of changes in levels of confidence and activity

While the original Likert scale was on five points, variations may be suitable, such as a four-point scale without a neutral response [39]. A four-point scale was selected for confidence and activity levels in order to avoid neutral and, sit on the fence, responses [40]. A five-point scale with a neutral response was used to explore perceive success factors and challenges, as some factors may not be applicable to certain buildings and occupants. In the surveys, an open essay section for additional comments was also included in order to capture potentially overlooked factors.

\section{Results}

The final competition rankings and corresponding percentual changes in power consumption from the baseline can be seen in Table 2. The change from the baseline is based on energy consumption in relation to the baseline year, with negative and positive values indicating energy conservation and increased power consumption, respectively. The top four ranked buildings achieved energy-savings, while the remaining in fact saw a rise in electricity consumption during the competition. In an attempt to explain these variations, the key success factors and challenges as reported during the interviews and surveys are shared as follows.

Table 2. Final competition rankings and energy conservation.

\begin{tabular}{ccc}
\hline Building & Rank & Change from Baseline \\
\hline A & 1 & $-23.16 \%$ \\
\hline B & 2 & $-14.18 \%$ \\
\hline C & 3 & $-8.08 \%$ \\
\hline D & 4 & $-1.73 \%$ \\
\hline E & 5 & $+10.42 \%$ \\
\hline F & 6 & $+12 \%$ \\
\hline G & 7 & $+12.84 \%$ \\
\hline H & 8 & +15.29 \\
\hline
\end{tabular}

\subsection{Interview Findings}

Based on content analysis of interview transcripts, challenges and success factors of energy conservation reported by interviewees in two or more buildings were identified. Key challenges discussed by the interviewees, as seen in Table 3, are explained as follows:

1. Comfort: Negative effects on thermal comfort (high temperatures and humidity levels) due to decreased air-conditioning (AC). This was discussed as an important element to maintain work productivity.

2. Contingencies: Incidents and factors out of occupant control, such as power outages and office appliances, were expressed as vital considerations for improved competition fairness.

3. Lack of control: Low level of control, such as of thermostat set-points, schedules and lighting sensors, in automated systems. Interviewees also reported system issues, such as deficient light sensor sensitivity and overly high/low AC temperatures. A mix of automatic and manual control 
was mentioned by one interviewee as a potential way to maintain comfort levels while also leveraging automation.

4. Lack of information: A need for improved information and communication was reported, with clear expectations and targeted information during the competition. Interviewees noted that introductory meetings could aid in this.

5. Lack of coordination: Interviewees reported difficulties in contacting facility managers, who could help occupants in energy reduction efforts, e.g., through set-point modifications and updating outdated equipment which are more energy-intensive.

6. Lack of involvement: A need for further involvement at the onset of competition-planning was reported. As one interviewee explained: "We want to show that we are doing our part ... but we need planning time."

Table 3. Key challenges for energy conservation in the Battle of the Buildings competition (BoB), as reported by two or more interviewees $(\checkmark$ : reported during interview).

\begin{tabular}{ccccccc}
\hline & (1) Comfort & $\begin{array}{c}\text { (2) Lack of } \\
\text { Control }\end{array}$ & $\begin{array}{c}(3) \\
\text { Contingencies }\end{array}$ & $\begin{array}{c}\text { (4) Lack of } \\
\text { Information }\end{array}$ & $\begin{array}{c}\text { (5) Lack of } \\
\text { Involvement }\end{array}$ & $\begin{array}{c}\text { (6) Lack of } \\
\text { Coordination }\end{array}$ \\
\hline A & $\checkmark$ & & $\checkmark$ & & & \\
B & $\checkmark$ & $\checkmark$ & $\checkmark$ & & & $\checkmark$ \\
C & $\checkmark$ & $\checkmark$ & $\checkmark$ & $\checkmark$ & & $\checkmark$ \\
E & $\checkmark$ & $\checkmark$ & $\checkmark$ & $\checkmark$ & $\checkmark$ & $\checkmark$ \\
G & $\checkmark$ & & $\checkmark$ & $\checkmark$ & $\checkmark$ & \\
\hline
\end{tabular}

Reported success factors are shown in Table 4, with communication as the only factor mentioned strongly by all interviewees. The top three buildings (A, B, C) emphasized all factors in Table 3, with the exception of the winning building (A), and the factor (7) project champion. building A interviewees explained that collective leadership rather than a single project champion enabled occupant engagement and conservation efforts. The reported success factors are described as follows:

1. Engagement: Reported as vital for energy savings by providing conducive social settings. As expressed by an occupant in Building C: "The strong group dynamics was a main driver. The competition was something we cared about, that we could engage in together."

2. Collective thinking: It was expressed that, through collective ideation and cooperation, higher energy savings was achievable. Collective approaches were reported to enable shared routines for energy use reduction.

3. Communication: Communication, internally among co-workers and externally, with the BoB organizers. This was discussed as a facilitator for energy-saving tips shared within co-worker teams, involvement in competition planning, and for regular feedback from competition organizers. Building A interviewees further explained that the self-organized kickoff meeting was influential for knowledge-sharing among co-workers, higher occupant engagement, and participation. As put by one occupant: "Brainstorming made us all get together, share ideas, and look at how to conserve energy. The brainstorming helped us attain full engagement."

4. Competitiveness: Discussed by interviewees as a facilitator of mindfulness of energy use and follow-through on conservation measures.

5. Performance visualization: Interviewees explained that the ability to see real-time performance of all buildings contributed to competitiveness, gratification, and motivation.

6. New habit development: Interviewees in the top three buildings explained that with increased awareness and mindfulness spurred by the competition, conservation measures were adopted from its onset. As expressed by an interviewee: "The competition helped people be more aware, change mindsets and conserve energy. At the end of the competition, things became more of a habit which will be sustained." 
7. Project champion: A leader or advocate within the building to encourage energy saving measures, and keep building occupants informed on competition progress.

Table 4. Key success factors for energy conservation in the BoB, as reported by two or more interviewees $(\checkmark$ : reported during interview).

\begin{tabular}{cccccccc}
\hline & $\begin{array}{c}\text { (1) Full } \\
\text { Engagement }\end{array}$ & $\begin{array}{c}\text { (2) Collective } \\
\text { Thinking }\end{array}$ & $\begin{array}{c}\text { (3) } \\
\text { Communication }\end{array}$ & $\begin{array}{c}\text { (4) } \\
\text { Competitiveness }\end{array}$ & $\begin{array}{c}\text { (5) Progress } \\
\text { Visualization }\end{array}$ & $\begin{array}{c}\text { (6) New Habit } \\
\text { Development }\end{array}$ & $\begin{array}{c}\text { (7) Project } \\
\text { Champion }\end{array}$ \\
\hline A & $\checkmark$ & $\checkmark$ & $\checkmark$ & $\checkmark$ & $\checkmark$ & $\checkmark$ & \\
B & $\checkmark$ & $\checkmark$ & $\checkmark$ & $\checkmark$ & $\checkmark$ & $\checkmark$ & $\checkmark$ \\
C & $\checkmark$ & $\checkmark$ & $\checkmark$ & $\checkmark$ & $\checkmark$ & $\checkmark$ & $\checkmark$ \\
E & & & $\checkmark$ & & & $\checkmark$ \\
G & & $\checkmark$ & & & $\checkmark$ \\
\hline
\end{tabular}

\subsection{Survey Findings}

The survey was completed with a response rate of $15.5 \%$ (27 respondents). Challenges and success factors as rated by respondents can be seen in Tables 5 and 6, respectively. The survey indicates that the challenges which the highest number of respondents rated, important, or, very important, involve (1) devices needed for work, (2) comfort, and (3) memory (to conduct energy-conserving activities). However, as seen in the $p$-values of the Chi-square test, all findings in Table 5 were found to be statistically insignificant, with the exception of lack of time ( $p$-value $=0.002$ ), which was rated by a minority of $4 / 27$ as important and by no respondents as very important. A lack of information on and thereby awareness of the competition, which led to zero or low rates of participation in some buildings, was also commented on in the open essay section of the survey.

In terms of success factors, as seen in Table 6, all factors were rated as important, or very important, by a majority of respondents with the exception of, prize motivation, and, internal incentives/competitions. The factors with the highest number of, important, or, very important, ratings include (1) team effort, (2) increased awareness, and (3) the competition as a reminder to conserve energy. All surveyed success factors were found to give statistically significant indications based on a Chi-square test ( $p$-value $<0.005)$, with the exception of, prize motivation, and, motivated to lead sustainable lifestyle.

Table 5. Challenges rated in order of importance by BoB participants.

\begin{tabular}{|c|c|c|c|c|c|c|}
\hline & Unimportant & $\begin{array}{l}\text { Somewhat } \\
\text { Important }\end{array}$ & $\begin{array}{l}\text { Neutral } \\
\text { (N/A) }\end{array}$ & Important & $\begin{array}{c}\text { Very } \\
\text { Important }\end{array}$ & $\begin{array}{c}\text { Chi-Square Test } \\
\text { ( } p \text {-Value) }\end{array}$ \\
\hline Lack of time & 13 & 4 & 6 & 4 & 0 & 0.002 \\
\hline Memory & 3 & 9 & 4 & 7 & 4 & 0.323 \\
\hline Lack of leadership & 10 & 6 & 7 & 3 & 1 & 0.058 \\
\hline Co-workers not interested & 3 & 10 & 6 & 3 & 5 & 0.188 \\
\hline $\begin{array}{l}\text { Lack of knowledge on } \\
\text { how to reduce energy use }\end{array}$ & 7 & 6 & 8 & 5 & 1 & 0.248 \\
\hline $\begin{array}{l}\text { Energy intensive devices } \\
\text { needed for work }\end{array}$ & 2 & 7 & 6 & 8 & 4 & 0.367 \\
\hline Inconvenience & 4 & 9 & 6 & 6 & 2 & 0.284 \\
\hline Sacrificed comfort & 3 & 8 & 4 & 6 & 6 & 0.589 \\
\hline
\end{tabular}

With regard to reported levels of activity and confidence in abilities to reduce energy consumption, an increased proportion of the participants reported being, active, or, very active, as well as, confident, or, very confident, after the BoB. The replies per respondent can be seen in Appendix A (Figure A1: Activity, Figure A2: Confidence). In this study, 16 respondents reported an increase in confidence, and 17 an increase in activity. Nine of the 11 respondents which showed no change in confidence reported to already be, confident or very confident, prior to the $\mathrm{BoB}$, while the remaining two reported to be, 
somewhat confident. In terms of activity, in addition to those reporting an increase, one respondent reported a decrease (active to somewhat active), five reported to already be, active or very active, before the BoB with no change post-competition, and four reported to be, somewhat active or inactive, with no change. Based on a two-tailed paired sample t-test of respondents' ratings before and after the BoB (Appendix A), the changes were found to be statistically significant ( $p$-value of $3.2 \times 10^{-5}$ for activity, and $3 \times 10^{-5}$ for confidence). In addition, it was commented in the survey essay section that in some areas, electrical outlets are inaccessible and sensors alone control some devices, inhibiting energy conservation activity. This is turn may lead to low levels of occupant control, similarly to what was expressed during the interviews.

Table 6. Success factors rated in order of importance by BoB participants.

\begin{tabular}{ccccccc}
\hline & Unimportant & $\begin{array}{c}\text { Somewhat } \\
\text { Important }\end{array}$ & $\begin{array}{c}\text { Neutral } \\
\text { (N/A) }\end{array}$ & Important & $\begin{array}{c}\text { Very } \\
\text { Important }\end{array}$ & $\begin{array}{c}\text { Chi-Square Test } \\
(p \text {-Value })\end{array}$ \\
\hline Leadership & 4 & 2 & 3 & 7 & 11 & 0.043 \\
\hline Team effort & 0 & 1 & 2 & 5 & 19 & $3.3 \times 10^{-9}$ \\
\hline Strategy and routines & 1 & 3 & 3 & 8 & 12 & 0.005 \\
\hline $\begin{array}{c}\text { Support and communication } \\
\text { among co-workers }\end{array}$ & 0 & 0 & 4 & 10 & 13 & $3.5 \times 10^{-5}$ \\
\hline Energy saving tips & 1 & 5 & 2 & 9 & 10 & 0.017 \\
\hline Prize motivation & 7 & 5 & 3 & 6 & 6 & 0.790 \\
\hline Increased awareness & 1 & 1 & 1 & 11 & 13 & $1.8 \times 10^{-5}$ \\
\hline $\begin{array}{c}\text { The competition as a } \\
\text { reminder to conserve energy }\end{array}$ & 1 & 1 & 1 & 14 & 10 & $1.0 \times 10^{-5}$ \\
\hline $\begin{array}{c}\text { Internal } \\
\text { incentives/competitions }\end{array}$ & 2 & 4 & 14 & 3 & 4 & 0.001 \\
\hline $\begin{array}{c}\text { Motivated to lead sustainable } \\
\text { lifestyle }\end{array}$ & 2 & 7 & 2 & 9 & 7 & 0.106 \\
\hline
\end{tabular}

\subsection{Post-Competition Findings}

The interviews and surveys captured perceptions linked to the BoB competition term. In order to understand potential long-term effects on occupant behavior, energy consumption following the BoB was investigated. In the six months following the BoB, it can be seen in Figure 3 that energy consumption levels tended to converge over time for all buildings. Buildings that were lower ranked at the end of the BoB showed improved energy conservation in relation to the previous year's baseline, while higher ranked buildings either maintained or increased energy consumption. While an in-depth investigation of these post-competition trends is outside the scope of this study, these findings potentially indicate rebound effects, which are included in the discussion of this paper.

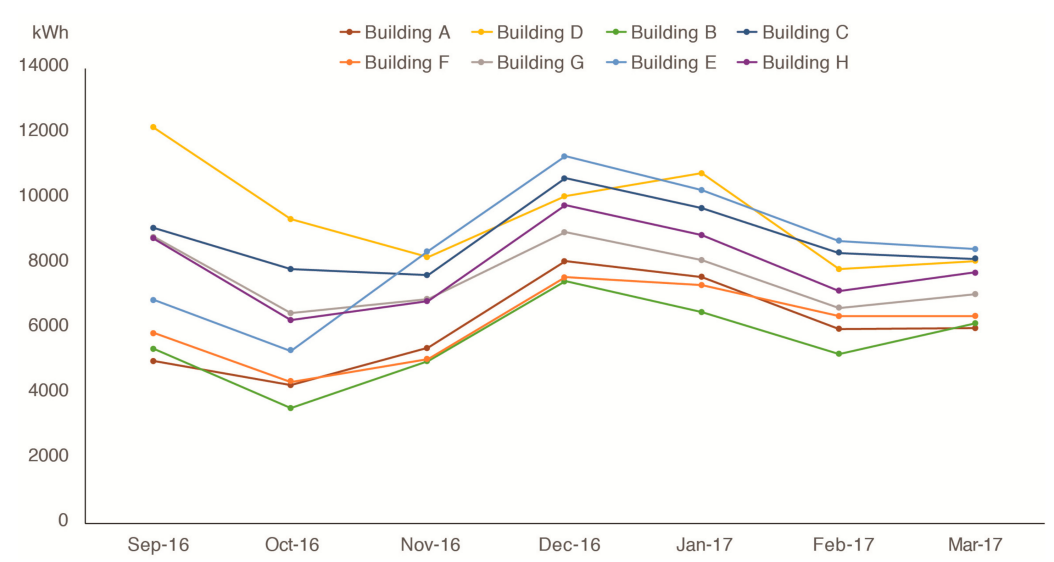

Figure 3. Energy consumption six months following the conclusion of the BoB. 


\section{Discussion}

Before discussing the results, it is important to mention that the survey response rate was low (15.5\%: 27 respondents) and the top three ranked buildings accounted for $56 \%$ of total responses. This incurs potential participation and non-response biases. The main challenges reported in the interviews of this study by lower ranked buildings, such as a lack of information and of involvement, were not as clearly shown in the survey responses or comments. Therefore, it is of importance to consider both the interviews and surveys of this study when discussing possible indications. Considering the variation of performance during the competition, indications of occupant behavior determinants that influenced this variation are discussed as follows. These determinants may thereafter be of interest to be explored further in future research.

\subsection{Key Success Factors}

The most frequently reported success factors during the interviews, among both higher and lower ranked buildings, involved communication among co-workers, and project champions, or advocates. A project champion was interestingly not emphasized by interviewees in the winning building, Building A. Interviewees in Building A rather highlighted the importance of collective leadership and a group effort for energy conservation. This indicates that the need of a leader among the occupants is uncertain. In the survey results, a significant majority ranked communication, collective effort, as well as leadership as, important or very important. Staddon et al. [21] similarly emphasized the role of group dynamics, social interaction, and middle management in influencing behavioral change in the office context. Numerous authors also discussed the importance of social influence, or public perception, as an important psychosocial motivator in feedback systems [24,29]. Similarly, it can be suggested that the collective effort and engagement expressed to have taken place in higher ranked buildings strengthened the occupants' reduction in energy consumption. This may be related to the development of social settings for occupant behavior change, linkable to the element of subjective norms or public perception in the TPB. Konis et al. [4] also found strong group identification and public perception to be linked to higher energy conservation in student dormitory competitions.

Interviewees also discussed competitiveness among peers as a success factor, and real-time progress visualization as a driver of this competitiveness, as well as of awareness of impacts on energy consumption. This feedback increased awareness of energy data as well as direct capabilities to affect it. However, it is important to note that it was interviewees in the top three ranked buildings that emphasized these points during the interviews. Moreover, Building B interviewees noted that occupants were competitive because their field of work and activities are related to the competition in terms of building technology and energy. However, other high-ranked buildings conduct a variety of activities, such as legal or retirement services. It is uncertain if the activities carried out in a building affects occupant engagement in energy conservation programs-potentially an area of interest for further research. The remaining interviewees in Buildings $E$ and $G$ noted that there was a lack of engagement and attention to energy visualization in their respective buildings. This indicates that approaches for engagement, including visualization, may be of interest for further exploration. It is suggested that the feedback obtainable from energy consumption visualization may influence the perceptions of consequences (attitude) and perceived control of energy consumption, under the TPB. Inyim et al. [6] also emphasized the potential of comparative feedback in relation to peers to stimulate individual energy use reduction. Real-time targeted feedback has indeed been found useful in promoting energy conservation through information and comparison-based strategies in numerous previous studies [10,14].

As seen in survey results, there are no clear indications that the motivation of a prize or internally created incentives, are widely considered as an important success factor. In addition, the influence of a prize, as well as motivation to lead a sustainable lifestyle, yielded non-significant results. This may not mean that these factors are to be ruled out, but rather suggests that other factors may have been more influential for energy conservation during the competition. Furthermore, energy-saving tips 
and increased awareness were ranked as important success factors. Inyim et al. [6] highlighted the potential of personalized feedback and tips consistent with occupants' behavior based on real-time data in building energy-saving interventions. Staats et al. [22] found that personalized as well as collective feedback contributed to gas consumption reduction in an office building.

New habit development was reported as a success factor in the interviews, and strategy and routines, in the surveys. The top three ranked buildings noted habit development in the interviews. The competition as a reminder to conserve energy, was also seen in the surveys as a significant success factor. It can be suggested that awareness, routines, and habits were potential success factors for energy conservation. The multidimensionality of long-term change, as explained by Frank [34], involves behavioral change as a systemic undertaking which may lead to the replacement of old standpoints and habits. This paper can demonstrate short-term behavioral change that attempts to offer useful insights on drivers that may begin to stimulate such change. It is essential, however, to differentiate between short- and long-term behavioral change.

In terms of the TPB, the short-term behavioral change explored in this study may be linked to intention driven by self-efficacy and temporary attitude changes rather than habituation. Knussen \& Yule [33] and Konis et al. [4] discussed similar prospects. The long-term effect of the competition is questionable, also considering the convergence of energy consumption levels following the BoB. In terms of the five-domain experiential system [34], this indicates that the emotional and worldview-related domains were not influenced for long-term change, but rather rationality in the short-term. In regards to the rebound effects and convergence of post-competition energy conservation levels seen among the participating buildings, it would be of interest to further explore long-term occupant behavior change. Furthermore, it may be important to consider that these post-competition trends may be linkable, not only to occupant behavior, but also other factors, such as varying occupancy. In order to understand the transformation of short-term behavioral change to long-term impact through habit modification, further research on the dynamics of this transformation and how to sustain it is needed.

\subsection{Key Challenges}

There are also a series of reported challenges in the interviews. All interviewees noted decreased thermal comfort as well as contingencies as key challenges for energy conservation. Thermal comfort can pertain to levels of illuminance, indoor air temperatures, and air quality such as humidity [13]. In the current study, interviewees described decreased comfort with regard to an increase in indoor temperature and humidity levels. Contingencies pertain to factors out of the participants' control, such as certain office appliances and automated systems. Lack of control was also noted as a challenge during the interviewees, among both higher and lower ranked buildings. In the surveys, it was also commented that an increased control of office devices, such as accessible outlets and sensors, can further contribute to energy conservation activity.

Interviewees in lower ranked buildings also reported a higher number of challenges, including lacking involvement in competition-planning, information, coordination, and control of appliances. Such challenges may have inhibited the attitude, social group dynamics, and perceived control needed for behavioral change as advocated by the TPB [30]. As highlighted by McKenzie-Mohr [28], it is imperative to find and address barriers of change in specific groups, corresponding to community-based social marketing. This may indicate that information-sharing and inclusive management would need to be improved at the onset and throughout the competition, for enhanced coordination and engagement. With improved participant involvement and coordination, for example via competition co-planning, it can be suggested that prospects to find and address barriers may be managed.

The survey results related to perceived challenges at large show non-significant findings with the exception of, a lack of time, to carry out energy conserving-activities. This was ranked by a majority as an unimportant or somewhat important challenge of energy conservation during the competition. A challenge noted by all interviewees, comfort, was ranked by $12 / 27$ respondents as important or very important. This significance is uncertain as nearly the same quantity (11/27) rated this as unimportant 
or somewhat important. Experiences of challenges seemed to vary more than of success factors. The statistically stronger indications for success factors as opposed to perceived challenges may suggest, (1) a need for further studies on potential challenges of occupant behavior change for energy conservation, and (2) further exploration on how to leverage identified success factors.

When contrasting the challenges and success factors reported by lower and higher ranked buildings, it can be suggested that there is a need for improved communication internally within buildings, as well as among participants and competition coordinators. The main challenges reported distinctively by interviewees in lower ranked buildings included lacking involvement and information. This could potentially be tackled with strategies leveraging the success factors reported by higher ranked buildings, such as collective team work, communication, and engagement. This is considering the positive impacts of co-worker engagement on memory to conduct energy-conserving measures, as reported by interviewees in higher ranked buildings. Adopting both top-down managerial policies and bottom-up engagement strategies may be important in successfully influencing occupant behavior, similarly highlighted by Elsharkawy and Rutherford [29]. It would be important to support communication among occupants to leverage elements of social influence in energy conservation interventions [6]. In this context, it is suggested that relationship management would be important for improved coordination among all relevant players, and control and involvement among participants. Increased communication channels, such as between facility managers and occupants, may for example contribute to overcoming to the challenge of a lack of device control and abilities to influence office power consumption among occupants.

\subsection{Multi-Dimensionality of Behavioral Change}

The reported success factors and challenges concern both the individual experiences of participants, such as awareness and memory, and group dynamics such as social learning and team efforts. It can be suggested that behavioral change in commercial building energy competitions is linkable to both individual and organizational dimensions, similarly highlighted by Staddon et al. [21]. These two dimensions can be analyzed in terms of price, psychology, physical elements, personal factors, public perception, and policy, as seen in the 6-P framework [26]. Price is omitted for this study, as electricity costs were not relevant to occupants in the BoB. In terms of individual psychology, the competition and progress visualization were expressed as reminders to conserve energy, and facilitators of awareness of energy consumption. Physical elements involve building and technology features, such as of thermostat adjustability. In terms of personal factors, findings indicated that occupants perceived the creation of new habits, strategy and routines as success factors. In terms of public perception, emphasis by occupants on collective engagement, communication among co-workers, and a team effort, indicates the importance of subjective norms and conducive social settings. As for the policy element of the 6-P framework, the BoB can be seen as a top-down initiative for change. However, the importance of bottom-up involvement for occupant engagement and coordination, in addition to building awareness about energy conservation, is highlighted by several authors [25-27] as well as by BoB participants.

This multidimensionality of behavioral change can also be discussed based on the TPB [30], which states that an action can be managed through creating a positive affiliation with perception of consequences (attitude), instilling confidence in an ability to carry out the behavior (control), and leveraging social influence (subjective norms). These three constructs are arguably influential for the success of the top three contestants of the BoB. At large, the surveys show significant results that suggest a general increase in confidence and activity related to energy conservation among the participants following the BoB. This might suggest that the competition facilitated an increase in perceived control and attitudes towards energy conservation. Moreover, several respondents who reported no change nonetheless also reported higher levels of confidence and activity already before the BoB.

Through the real-time visualization of building performance, it is suggested that potential positive consequences (attitude), as well as abilities to conserve energy (control) were clarified. Keskin and Menguc [7] similarly discussed mobile platforms as a facilitating condition under the 
TIB for visualization of thermostat energy savings, to demonstrate ease of use, and to provide direct feedback. In addition, the importance of public perception as discussed earlier, involving factors such as, team effort and collective thinking, indicates the importance of subjective norms and social influence among peers. Interviewees in top-ranked buildings also highlighted the importance of competitiveness for energy conservation during the competition. Mobile platforms, such as smart phone applications, may also be leveraged in social sharing, learning [7], as well as for competition and peer-comparison purposes.

The findings indicate that both technical and social aspects would be important considerations when developing approaches for occupant behavior for energy conservation. Following this, Roberti et al. [20] demonstrated in simulations that technical measures for building energy conservation can be strengthened by incorporating occupant behavior, especially pertaining to the management of heating, ventilation, and air-conditioning. The authors found that behavior, such as opting for natural ventilation, can add to energy conservation coupled with technical measures, such as improved insulation [20]. In future developments and research, it would be important to explore and discuss the integration of social and technological approaches to occupant behavior for energy conservation.

Considering the complex and interdisciplinary nature of occupant behavior [13], intervention and conservation approach development would benefit from multi-disciplinary teams [20]. It can be suggested that by incorporating various fields, such as engineering as well as social sciences, developments for energy conservation in commercial buildings can be expanded. With the single case study explored in this paper, findings are not generalizable to populations but may be useful in developing initial propositions related to occupant behavior and implications for future research and development. Based on the findings of this study, and on ensuing discussion, the following measures and their influence on occupant behavior in commercial building energy conservation competitions are suggested for further exploration:

1. Bottom-up involvement: For example, via (a) an introductory meeting and co-planning with all occupants and relevant facility managers, (b) kickoff/brainstorming meetings in each building, including facility managers, to discuss competition strategies and internal planning. This may contribute to several success factors, including involvement, coordination, leadership, team effort, strategy and routine creation, engagement, and communication among occupants.

2. Stakeholder relationship management: For example, pertaining to (a) improved relations among occupants and facility managers able to carry out adjustments, upgrades, or repairs of building equipment. It is suggested that the challenge of lacking (appliance) control can be tackled.

3. Targeted information: For example, (a) regular performance reports collectively for each building and for each individual coupled with targeted, actionable feedback on how to further improve energy conservation efforts. This may contribute further to success factors including energy saving tips, awareness, engagement, and the competition as a reminder to conserve energy.

4. Real-time visualization: For example, with (a) clearly shown progress demonstrating abilities to impact energy consumption, (b) peer comparison. This may contribute to success factors of the competition as a reminder to conserve energy, increased awareness, progress visualization, and competitiveness.

5. Mobile social platform: For example, (a) as a facilitating technology to support social interaction, information-sharing (feedback, tips), progress visualization, communication, and engagement in an integrated manner.

\section{Conclusions}

Occupant behavior and its influence on energy consumption in commercial buildings is a new and growing domain of research. This domain is important in efforts of energy conservation, building sustainability, and greenhouse gas emission reduction. This paper set out to explore determinants of occupant behavior for energy conservation in commercial buildings in the context of a specific 
intervention technique: An energy conservation competition. This was carried out by exploring the potential challenges and success factors of occupant behavior for energy conservation in a case study of a competition at the Oak Ridge National Laboratory. This case was investigated based on a mixed methods approach and explanatory research design leveraging energy data, participant interviews, and surveys. Energy conservation was seen solely in the top four out of eight buildings, with total reductions of $23.16 \%, 14.18 \%, 8.08 \%$ and $1.73 \%$ from the previous year's baseline. The remaining buildings showed a rise in energy consumption. Considering the variance of building performance during the competition, the determinants of occupant behavior and, of this variance, were of interest. The findings of challenges and success factors of occupant behavior for energy conservation incorporated both social and technological elements. Based on the findings and discussion, elements suggested for further research include social (bottom-up involvement, stakeholder relationship management), and technological measures (targeted information, energy consumption visualization, mobile social platforms). An important next step would also be to further investigate the measures and determinants for occupant behavior change from a long-term perspective, and how rebound effects can be avoided. This may be useful in facilitating the improvement of building energy efficiency and sustainability efforts in holistic approaches. This paper aims to contribute to this growing research domain with implications for both academia and practitioners.

Author Contributions: Conceptualization, A.A., B.H., T.N., M.L.; methodology, A.A., B.H., T.N., M.L., G.A.; software, G.A.; validation, A.A., B.H., T.N., G.A.; formal analysis, A.A., G.A., T.N.; investigation, A.A., G.A., T.N.; resources, G.A., T.N.; data curation, A.A., G.A.; writing-original draft preparation, A.A., T.N.; writing-review and editing, A.A., B.H., T.N., M.L., G.A.; visualization, G.A.; supervision, B.H., T.N., M.L.; project administration, B.H., T.N., M.L.

Funding: This research received no external funding.

Conflicts of Interest: The authors declare no conflicts of interest.

\section{Appendix A}

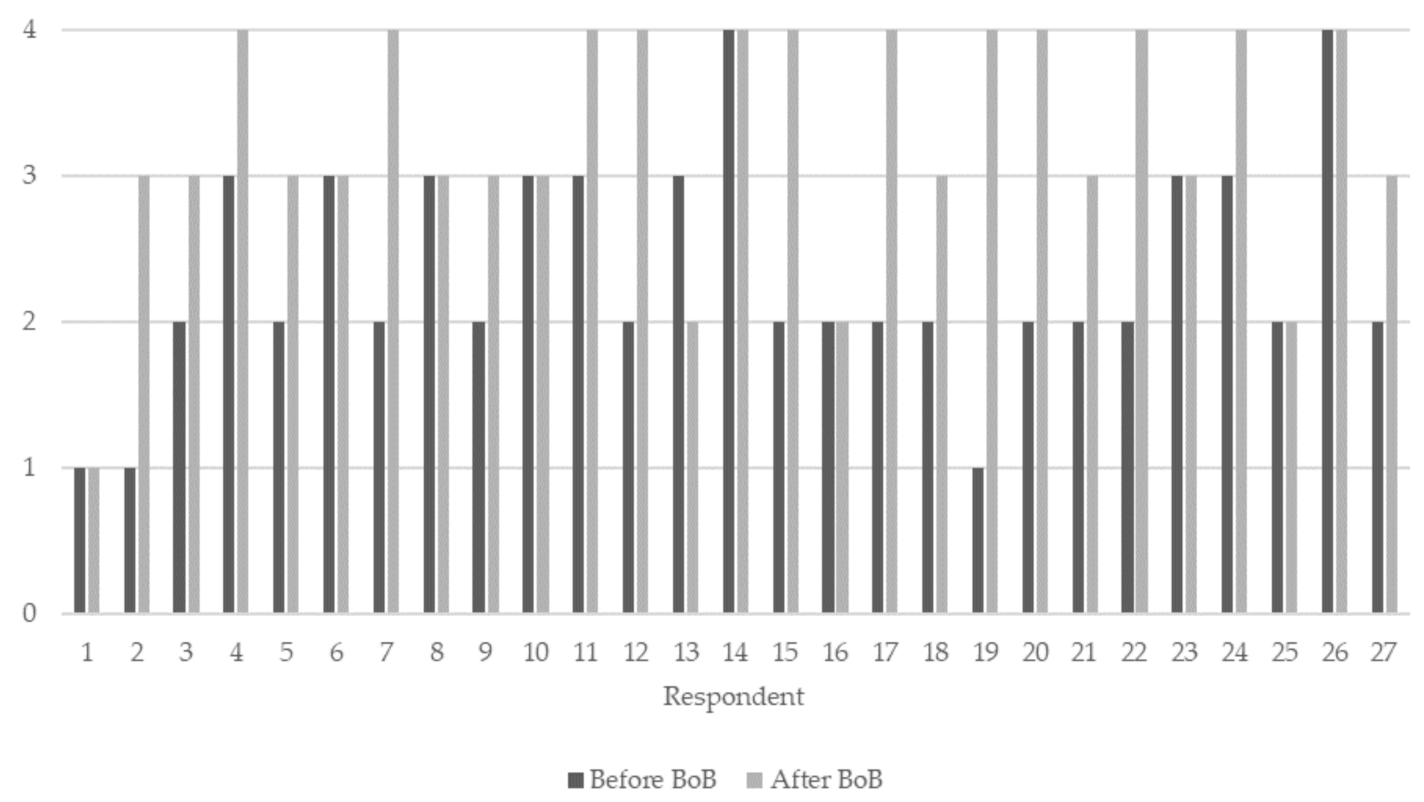

Figure A1. Level of activity for energy conservation reported before and after the competition by survey respondents (1: Inactive, 2: Somewhat active, 3: Active, 4: Very active). Average change: +0.93. Double tailed, paired sample t-test: $p$-value of change: $3.2 \times 10^{-5}$. 


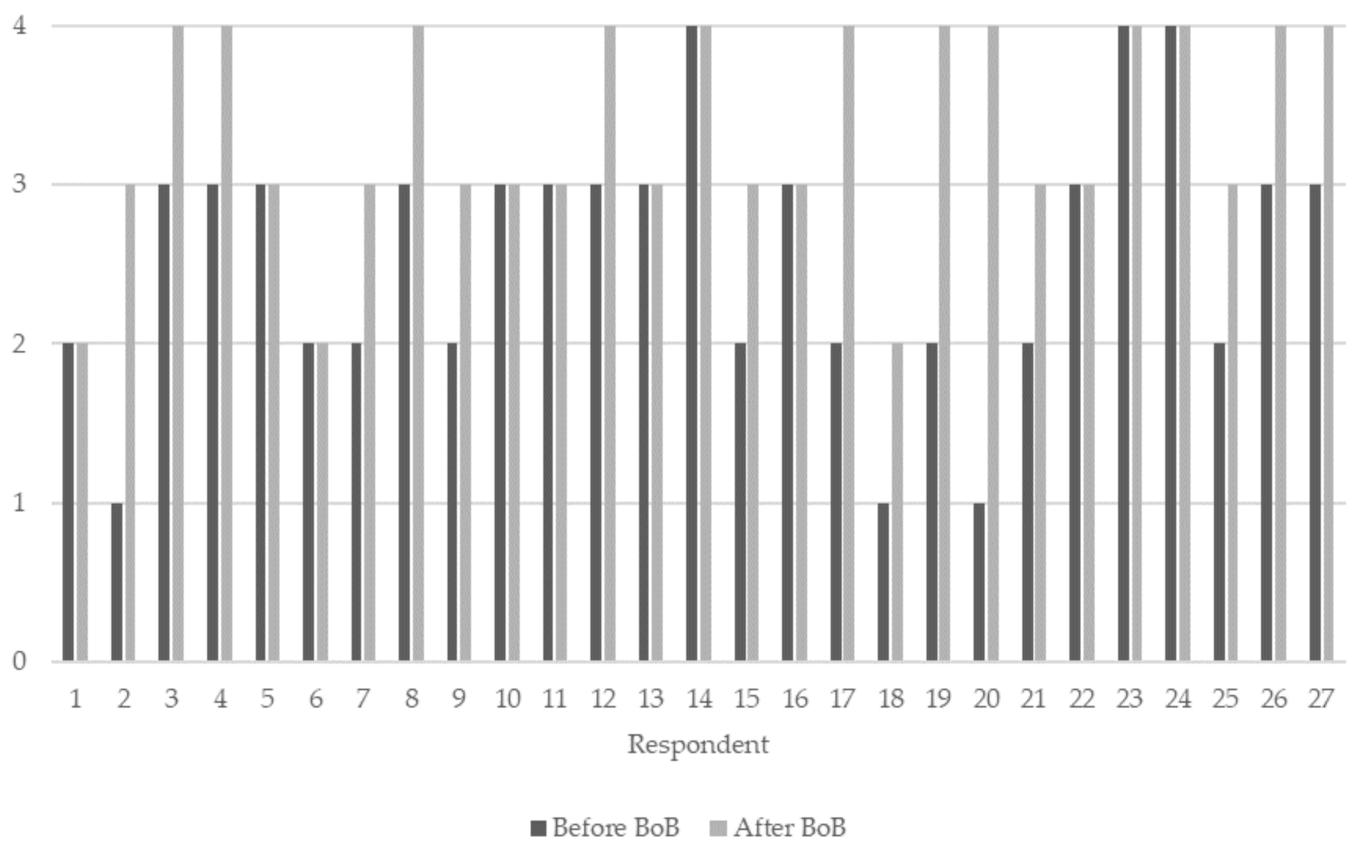

Figure A2. Level of confidence in abilities to conserve energy, reported before and after the competition by survey respondents (1: Unconfident, 2: Somewhat confident, 3: Confident, 4: Very confident) Average change: +0.78 . Double tailed, paired sample t-test: $p$-value of change: $3.0 \times 10^{-5}$.

\section{References}

1. Bolton, R.; Foxon, T.J. A socio-technical perspective on low carbon investment challenges-Insights for UK energy policy. Environ. Innov. So. Transit. 2015, 14, 165-181. [CrossRef]

2. Loorbach, D. Transition Management-New mode of governance for sustainable development. North 2007, 193, 301-314.

3. Zhao, D.; McCoy, A.P.; Du, J.; Agee, P.; Lu, Y. Interaction effects of building technology and residential behavior on energy consumption in residential buildings. Energy Build. 2017, 134, 223-233. [CrossRef]

4. Konis, K.; Orosz, M.; Sintov, N. A window into occupant-driven energy outcomes: Leveraging sub-metering infrastructure to examine psychosocial factors driving long-term outcomes of short-term competition-based energy interventions. Energy Build. 2016, 116, 206-217. [CrossRef]

5. Rafsanjani, H.N.; Ahn, C.R.; Chen, J. Linking building energy consumption with occupants' energy-consuming behaviors in commercial buildings: Non-intrusive occupant load monitoring (NIOLM). Energy Build. 2018, 172, 317-327. [CrossRef]

6. Inyim, P.; Batouli, M.; Reyes, M.P.; Carmenate, T.; Bobadilla, L.; Mostafavi, A. A Smartphone Application for Personalized and Multi-Method Intervention toward Energy-Saving in Buildings. Sustainability 2018, 10, 1744. [CrossRef]

7. Keskin, C.; Mengüc, M.P. On Occupant Behavior and Innovation Studies Towards High Performance Buildings: A Transdisciplinary Approach. Sustainability 2018, 10, 3567. [CrossRef]

8. Zhang, Y.; Bai, X.; Mills, F.P.; Pezzey, J.C.V. Rethinking the role of occupant behavior in building energy performance: A review. Energy Build. 2018, 172, 279-294. [CrossRef]

9. Heesen, F.; Madlener, R. Consumer behavior in energy-efficient homes: The limited merits of energy performance ratings as benchmarks. Energy Build. 2018, 172, 405-413. [CrossRef]

10. Kosonen, H.K.; Kim, A.A. Advancement of behavioral energy interventions in commercial buildings. Facilities 2017, 35, 367-382. [CrossRef]

11. Hong, T.; Taylor-Lange, S.C.; D'Oca, S.; Yan, D.; Corgnati, S.P. Advances in research and applications of energy-related occupant behavior in buildings. Energy Build. 2016, 116, 694-702. [CrossRef]

12. Nisiforou, O.; Poullis, S.; Charalambides, A. Behavior, attitudes and opinion of large enterprise employees with regard to their energy use habits and adoption of energy saving measures. Energy Build. 2012, 55, 299-311. [CrossRef] 
13. Pivac, N.; Nizetic, S.; Zanki, V. Occupant behavior and thermal comfort field analysis in typical educational research institution: A case study. Therm. Sci. 2018, 22, 13. [CrossRef]

14. Delmas, M.A.; Fischlein, M.; Asensio, O.I. Information strategies and energy conservation behavior: A meta-analysis of experimental studies from 1975 to 2012. Energy Policy 2013, 61, 729-739. [CrossRef]

15. Dietz, T.; Gardner, G.T.; Gilligan, J.; Stern, P.C.; Vandenbergh, M.P. Household actions can provide a behavioral wedge to rapidly reduce US carbon emissions. Proc. Natl. Acad. Sci. USA 2009, 106, 18452-18456. [CrossRef] [PubMed]

16. Asensio, O.I.; Delmas, M.A. Nonprice incentives and energy conservation. Proc. Natl. Acad. Sci. USA 2015, 112, E510-E515. [CrossRef] [PubMed]

17. Peterson, J.E.; Shunturov, V.; Janda, K.; Platt, G.; Weinberger, K. Dormitory residents reduce electricity consumption when exposed to real-time visual feedback and incentives. Int. J. Sustain. High. Educ. 2007, 8 , 16-33. [CrossRef]

18. Sintov, N.; Dux, E.; Tran, A.; Orosz, M. What goes on behind closed doors? How college dormitory residents change to save energy during a competition-based energy reduction intervention. Int. J. Sustain. High. Educ. 2016, 17, 451-470. [CrossRef]

19. Becherini, F.; Lucchi, E.; Gandini, A.; Barrasa, M.C.; Troi, A.; Roberti, R.; Sachini, M.; Di Truccio, M.C.; Arrieta, L.G.; Pockelé, L.; et al. Characterization and thermal performance evaluation of infrared reflective coatings compatible with historic buildings. Build. Environ. 2018, 134, 35-46. [CrossRef]

20. Roberti, F.; Oberegger, U.F.; Lucchi, E.; Gasparella, A. Energy Retrofit and Conservation of Built Heritage Using Multi-Objective Optimization: Demonstration on a Medieval Building. Available online: http://www.eurac.edu/en/research/technologies/renewableenergy/publications/Documents/ EURAC-RenEne_FRoberti-UFilippiOberegger-ELucchi-AGasparella_IBPSA-Italy2015.pdf (accessed on 27 March 2019).

21. Staddon, S.C.; Cycil, C.; Goulden, M.; Leygue, C.; Spence, A. Intervening to change behaviour and save energy in the workplace: A systemic review of available evidence. Energy Res. Soc. Sci. 2016, 17, 30-51. [CrossRef]

22. Staats, H.; Van Leeuwen, E.; Wit, A. A Longitudinal Study of Informational Interventions to Save Energy in an Office Building. J. Appl. Behav. Anal. 2000, 33, 101-104. [CrossRef]

23. United States Environmental Protection Agency (EPA). L'Oréal USA, I've Got the Power-Energy Conservation Challenge. Energy Star Buildings Partner Meeting (11 October 2012). Available online: https://www.energystar.gov/sites/default/files/buildings/tools/L\%27Oreal_I\%27ve_Got_The_Power.pdf (accessed on 27 March 2019).

24. Jain, R.K.; Gulbinas, R.; Taylor, J.E.; Culligan, P.J. Can social influence drive energy savings? Detecting the impact of social influence on the energy consumption behavior of networked users exposed to normative feedback. Energy Build. 2013, 66, 119-127. [CrossRef]

25. Nor Kalsum, I.M. Sustainable campus and academic staff awareness and behaviour in Malaysia's institutions of higher learning: A case study of UPSI. Malays. J. Soc. Space 2016, 12, 89-99.

26. Too, L.; Bajracharya, B.; Khanjanasthiti, I. Developing a Sustainable Campus through Community Engagement: An Empirical Study. Archit. Res. 2013, 3, 42-50.

27. Wu, A.; Singh, J.; Tikasz, P. Independent Study on Changing Student Behavior to Increase Energy Sustainability and Efficiency at the Macdonald Campus of McGill University. Cons. J. Sustain. Dev. 2013, 10, 154-179.

28. McKenzie-Mohr, D. Promoting Sustainable Behavior: An Introduction to Community-Based Social Marketing. J. Soc. Issues 2000, 56, 543-554. [CrossRef]

29. Elsharkawy, H.; Rutherford, P. Energy-efficient retrofit of social housing in the UK: Lessons learned from a Community Energy Savings Programme (CESP) in Nottingham. Energy Build. 2018, 172, 295-306. [CrossRef]

30. Ajzen, I. Perceived Behavioral Control, Self-Efficacy, Locus of Control, and the Theory of Planned Behavior. J. Appl. Soc. Psychol. 2002, 32, 665-683. [CrossRef]

31. Triandis, H.C. Interpersonal Behavior; Brooks/Cole Publishing Company: Monterey, CA, USA, 1977.

32. Bamberg, S.; Ajzen, I.; Schmidt, P. Choice of travel mode in the theory of planned behavior: The roles of past behavior, habit, and reasoned action. Basic Appl. Soc. Psychol. 2003, 25, 175-187. [CrossRef]

33. Knussen, C.; Yule, F. 'I'm Not in the Habit of Recycling' The Role of Habitual Behavior in the Disposal of Household Waste. Environ. Behav. 2008, 40, 683-702. [CrossRef] 
34. Frank, G. Becoming sustainable: Human determinants of change. Sci. Total Environ. 2014, 481, 674-680. [CrossRef]

35. Ruepert, A.; Keizer, K.; Steg, L.; Maricchiolo, F.; Carrus, G.; Dumitru, A.; Garcia Mira, R.; Stancu, A.; Moza, D. Environmental considerations in the organizational context: A pathway to pro-environmental behaviour at work. Energy Res. Soc. Sci. 2016, 17, 59-70. [CrossRef]

36. Yin, R.K. Case Study Research: Design and Methods (Applied Social Research Methods), 4th ed.; Bickman, L., Rog, D.J., Eds.; SAGE Publications Inc.: Thousand Oaks, CA, USA, 2009; Volume 5.

37. Zou, P.X.W.; Xu, C.; Sanjayan, J.; Wang, J. A mixed methods design for building occupants' energy behavior research. Energy Build. 2018, 166, 239-249. [CrossRef]

38. Eisenhardt, K.M. Building Theories from Case Study Research. Acad. Manag. Rev. 1989, 14, 532-550. [CrossRef]

39. Clason, D.L.; Dormody, T.J. Analyzing Data Measured by Individual Likert-Type Items. J. Agric. Educ. 1994, 35, 31-35. [CrossRef]

40. Brown, J.D. What issues affect Likert-scale questionnaire formats? Shiken JALT Test. Eval. SIG Newsl. 2000, 4, $27-30$.

(C) 2019 by the authors. Licensee MDPI, Basel, Switzerland. This article is an open access article distributed under the terms and conditions of the Creative Commons Attribution (CC BY) license (http://creativecommons.org/licenses/by/4.0/). 